\title{
Endothelium-independent vasodilation induced by kolaviron, a biflavonoid complex from Garcinia kola seeds, in rat superior mesenteric arteries
}

\author{
Oluwatosin A. AdARAMOYE ${ }^{1,2}$ and Isac A. MEdeIROS ${ }^{1}$ \\ ${ }^{1}$ Laboratório de Tecnologia Farmacêutica (LTF), Universidade Federal da Paraíba \\ (UFPB), Joâo Pessoa, Paraíba, Brazil \\ ${ }^{2}$ Drug Metabolism and Toxicology Unit, Department of Biochemistry, University of \\ Ibadan, Ibadan, Nigeria
}

Received November 5, 2008; Accepted December 26, 2008

\begin{abstract}
Previous studies have established the hepatoprotective, gastroprotective, hypolipidemic and hypoglycemic effects of kolaviron (KV), a biflavonoid complex from Garcinia kola seeds. In this study, we investigated the mechanisms involved in the vasorelaxant effects of $\mathrm{KV}$ in isolated superior mesenteric arteries from normotensive rats. $\mathrm{KV}(1,10,30,100$, 300,500 and $1,000 \mu \mathrm{g} / \mathrm{ml}$ ) concentration-dependently inhibited the contractions induced by phenylephrine (PHE) $(10 \mu \mathrm{M})$ and $\mathrm{KCl}(80 \mathrm{mM})$ in both endothelium-intact $\left(E_{\max }=58.3 \pm\right.$ $1.7 \%$ and $51.4 \pm 1.3 \%$, respectively) and -denuded rings $\left(E_{\max }=59.3 \pm 5.5 \%\right.$ and $64.3 \pm 2.4 \%$, respectively). Furthermore, $\mathrm{KV}$ reduced $\mathrm{CaCl}_{2}$-induced contraction in $\mathrm{Ca}^{2+}$-free medium containing $\mathrm{KCl} 60 \mathrm{mM}$, thus acting as a $\mathrm{Ca}^{2+}$-antagonist. In addition, $\mathrm{KV}$ inhibited the transient contraction by PHE in $\mathrm{Ca}^{2+}$-free medium containing EGTA, suggesting a possible action on the release of intracellular $\mathrm{Ca}^{2+}$ via the inositol-1,4,5-triphosphate $\left(\mathrm{IP}_{3}\right)$ pathway. $\mathrm{KV}$ is not a specific $\alpha$-adrenoceptor blocker, since it also caused a concentration-dependent inhibition of contractile responses to $\mathrm{KCl}$, suggesting that $\mathrm{KV}$ also blocks the L-type $\mathrm{Ca}^{2+}$ channel. As a Ca ${ }^{2+}$ antagonist, $\mathrm{KV}(100 \mu \mathrm{g} / \mathrm{ml})$ potentiates the relaxant effects of nifedipine in denuded rings $\left(E_{\max }=97.6 \pm 1.2 \%\right.$; control $\left.=75.1 \pm 3.0 \%, P<0.05\right)$. Also, the vasorelaxation induced by $\mathrm{KV}$ was significantly inhibited after pre-treatment of the denuded rings with 4aminopyridine (4-AP) $1 \mathrm{mM}$, a selective blocker of voltage-dependent $\mathrm{K}^{+}\left(\mathrm{K}_{\mathrm{v}}\right)$ channels and, tetraethylammonium (TEA) $1 \mathrm{mM}$ or charybdotoxin (ChTX) $0.1 \mu \mathrm{M}$, non-selective blockers of large and intermediate conductance $\mathrm{Ca}^{2+}$ activated $\mathrm{K}^{+}\left(\mathrm{BK}_{\mathrm{Ca}}\right)$ channels. In contrast, neither glibenclamide $(10 \mu \mathrm{M}), \mathrm{BaCl}_{2}(1 \mathrm{mM})$ nor apamin $(0.1 \mu \mathrm{M})$, blockers of $\mathrm{K}_{\mathrm{ATP}}, \mathrm{K}_{\mathrm{IR}}$ and $\mathrm{SK}_{\mathrm{Ca}}$ channels, respectively affected the $\mathrm{KV}$-induced vasorelaxation. In conclusion, our results provide functional evidence that the vasorelaxant effects by KV involve extracellular $\mathrm{Ca}^{2+}$ influx blockade, inhibition of intracellular $\mathrm{Ca}^{2+}$ release and the opening of $\mathrm{K}^{+}$channels sensitive to 4-AP and ChTX with a resultant membrane hyperpolarization/ repolarization.
\end{abstract}

Key words: $\mathrm{Ca}^{2+}$ influx, endothelium-independent, Garcinia kola, mesenteric artery, vasodilation

Correspondence to: Dr. Oluwatosin A. Adaramoye, Drug Metabolism and Toxicology Unit, Department of Biochemistry, University of Ibadan, Ibadan, Nigeria

Phone: +23-4-802-8835-954 Fax: +23-4-2-8103-043 e-mail: aoadaramoye@yahoo.com 


\section{Introduction}

Recently there has been an upsurge of interest in the therapeutic potentials of medicinal plants as antioxidants in alleviating oxidative stress-induced pathologies (Lans et al., 2007; Lee $e t$ $a l ., 2007)$. Several studies revealed that medicinal plants contain diverse classes of bioactive compounds such as polyphenols, tocopherols, alkaloids, etc. (Gordana et al., 2004; Lee et al., 2007). Among them, flavonoids are particularly attractive as they are known to exhibit various pharmacological properties such as vasoprotection, anti-carcinogenic, anti-microbial, antiinflammatory and anti-proliferative effects (Gordana et al., 2004). The health benefits of flavonoids have been linked to their actions as antioxidants, free radical scavengers, quencher of singlet and triplet oxygen and inhibitors of peroxidation reactions (Li-chem et al., 2006). Garcinia kola Heckel (Family; Guttiferae) is a herb grown in Nigeria with a characteristic astringent, bitter and resinous taste. This seed, also called "bitter kola" is eaten raw by the people with the belief that it promotes longevity. Extracts of the plant are used in traditional African medicine for the treatment of laryngitis, cough and liver diseases (Iwu and Igboko, 1982). Chemical investigations of the seed revealed the presence of Garcinia biflavanone (GB), xanthones, triterpenes and benzophenones (Cotterhill et al., 1978). The biflavanones are the most dominant in most Garcinia species (Waterman and Hussain, 1983). Kolaviron (KV), the predominant constituent in Garcinia kola is a biflavonoid complex that has been reported to prevent hepatotoxicity mediated by several toxins (Iwu et al., 1987; Adaramoye and Adeyemi, 2006a). Likewise, KV is known to exhibit hypoglycemic effects in normal, alloxan and streptozotocin-diabetic animals (Iwu et al., 1990; Adaramoye and Adeyemi, 2006b). Also, KV has been reported to elicit strong antioxidant activity in both in vivo and in vitro experimental models (Adaramoye et al., 2005a). In a preliminary study, we demonstrated that KV elicited hypocholesterolemic effects and reduced the relative weight of the heart in cholesterol fed animals (Adaramoye et al., 2005b), thus providing a background to explore the possible cardiovascular effects of this biflavonoid complex in rats. Accordingly, this study was designed to investigate the mechanisms involved in the vasorelaxant effects induced by $\mathrm{KV}$ in isolated rat superior mesenteric arteries.

\section{Methods}

\section{Animals}

Male Wistar rats (250-300 g) were used for all experiments. The animals were kept in wellventilated cages at controlled temperature $\left(21 \pm 1^{\circ} \mathrm{C}\right)$ and under controlled light cycles $(12 \mathrm{~h}$ light/12 h dark). They were maintained on normal laboratory chow (PURINA-Brazil) and tap water ad libitum. The study was approved by the Committee of Ethics for Animal Research (Comitê De Êtica Em Pesquisa Animal) CEPA No 0805/07, Laboratório de Tecnologia Farmacêutica, Universidade Federal da Paraíba, João Pessoa, Brazil. The protocols conform to the 1985 guidelines for laboratory animal care of the National Institute of Health (NIH). 


\section{Drugs}

The drugs used were: L-phenylephrine hydrochloride, acetylcholine hydrochloride, Tween80, nifedipine, barium chloride, tetraethylammonium, glibenclamide, charybdotoxin, apamin, 4aminopyridine, caffeine, ethyleneglycol bis ( $\beta$-aminoethylether)-N,N,N',N'-tetraacetic acid (EGTA) (Sigma Chemical Co., Saint Louis, MO, USA). Chemicals used for preparing Tyrode's solutions are; calcium chloride, glucose, magnesium sulphate, potassium dihydrogen phosphate, sodium bicarbonate and sodium chloride (E. Merck, Darmstadt, Germany). The stock solutions were dissolved in distilled water, except nifedipine and glibenclamide that were dissolved in ethanol. The solutions were prepared fresh on the day of experiments.

\section{Extraction of kolaviron ( $K V$ )}

Garcinia kola seeds were obtained commercially in Ibadan, Nigeria and certified at the herbarium in the Department of Botany, University of Ibadan, Nigeria, where a voucher specimen already exists (UI-00138/01). Three kilogram of peeled seeds was sliced, pulverized with an electric blender and air-dried in the laboratory $\left(25-28^{\circ} \mathrm{C}\right)$. Extraction of $\mathrm{KV}$ was achieved by the methods of Cotterhill et al. (1978) and Iwu et al. (1990). Briefly, powdered seeds were extracted with light petroleum ether $\left(\mathrm{bp} 40-60^{\circ} \mathrm{C}\right)$ in a soxhlet extractor. The defatted, dried marc was repacked and then extracted with methanol. The extract was concentrated and diluted to twice its volume with distilled water and extracted with ethyl acetate $(6 \times 250 \mathrm{ml})$. The concentrated ethyl acetate fraction gave a yellow solid known as kolaviron (KV) (Fig. 1) with a percentage yield of 6\%. KV was dissolved in 2-3 drops of tween-80 and diluted to desire concentrations with distilled water to give a water-soluble fraction. The drug solutions were prepared fresh on the day of experiments.

\section{Preparation of isolated rat superior mesenteric artery rings}

The superior mesenteric arteries from the second order branches were quickly removed and cleaned of adherent connective tissues and fat. Mesenteric rings (2-4 mm length) were obtained and suspended by cotton threads in organ bath containing $10 \mathrm{ml}$ Tyrode's solution, maintained at $37^{\circ} \mathrm{C}$ and gassed with a $95 \% \mathrm{O}_{2}+5 \% \mathrm{CO}_{2}$ mixture $(\mathrm{pH} 7.4)$. The composition of the Tyrode's solution (in $\mathrm{mM}$ ): $\mathrm{NaCl} 158.3 ; \mathrm{KCl} 4.0 ; \mathrm{CaCl}_{2} \cdot 2 \mathrm{H}_{2} \mathrm{O}$ 2.0; $\mathrm{MgCl}_{2} \cdot 6 \mathrm{H}_{2} \mathrm{O}$ 1.05; $\mathrm{NaHCO}_{3}$ 10.0; $\mathrm{NaH}_{2} \mathrm{PO}_{4} \cdot \mathrm{H}_{2} \mathrm{O} 0.42$ and Glucose 5.6 (Tanaka et al., 1999). Rings were stabilized with a resting tension of $0.75 \mathrm{~g}$, for at least $60 \mathrm{~min}$, with constant changing of Tyrode's solution (every $15 \mathrm{~min}$ ) to prevent the accumulation of metabolites that could otherwise lead to misinterpretation of results (Altura and Altura, 1970). The isometric tension was recorded by a force-displacement transducer (Miobath-4, WPI, Sarasota, FL, USA) coupled to an amplifierrecorder (Transbridge-4; WPI, Sarasota, FL, USA) and a computer equipped with an analog-todigital converter board (AD16JR; WPI, Sarasota, FL, USA). In some experiments, the endothelium layer of the rings was removed by gently rubbing the external surface with a finger moistened with Tyrode's solution. Endothelial integrity was assessed qualitatively by the degree of relaxation caused by acetylcholine $(10 \mu \mathrm{M})$ in the presence of contractile tone induced by phenylephrine (PHE, $10 \mu \mathrm{M}$ ). Rings were considered to be endothelium-denuded when acetylcholine-induced relaxant effects were less than $10 \%$ and, endothelium-intact when the 
HO<smiles></smiles>

$\begin{array}{lllll} & \text { R1 } & \text { R2 } & \text { R3 } & \text { R4 } \\ \text { GB1 } & \text { OH } & \text { H } & \text { OH } & \text { H } \\ \text { GB2 } & \text { OH } & \text { H } & \text { OH } & \text { OH } \\ \text { Kolaflavanone } & \text { OH } & \text { H } & \text { OMe } & \text { OH }\end{array}$

Fig. 1. Structure of kolaviron.

relaxant effects were more than $90 \%$.

Effect of $K V$ on sustained contractions induced by phenylephrine or KCl in isolated preparations from rat superior mesenteric arteries

After equilibration, steady tension was evoked by PHE $(10 \mu \mathrm{M})$ for endothelium-intact and -denuded rings to induce contraction of similar magnitude and KV was added cumulatively (1, $10,30,100,300,500$ and $1,000 \mu \mathrm{g} / \mathrm{ml})$. The ability of $\mathrm{KV}$ to attenuate the $80 \mathrm{mM} \mathrm{KCl}$-induced sustained contraction in the rings was also examined. For comparison, the vasorelaxant effect of nifedipine $\left(10^{-14}-10^{-5} \mathrm{M}\right)$, a blocker of voltage-dependent $\mathrm{Ca}^{2+}$ channels (Priviero et al., 2006), was also evaluated against the contractions induced by $\mathrm{PHE}$ or $\mathrm{KCl}$, in both, endothelium-intact and -denuded rings. Furthermore, the ability of $\mathrm{KV}(10,30$ and $100 \mu \mathrm{g} / \mathrm{ml})$ to ameliorate the vasorelaxant effects of nifedipine $\left(10^{-14}-10^{-5} \mathrm{M}\right)$ in endothelium denuded rings pre-contracted with PHE was studied. The relaxations were measured by comparing the developed tension before and after addition of KV or nifedipine. 
Investigation of the role of $K^{+}$channels in the $K V$-induced vasorelaxant response in isolated rat superior mesenteric arteries

In another set of experiments, the rings without endothelium were pre-contracted with PHE $(10 \mu \mathrm{M})$ for $30 \mathrm{~min}$ after being pre-incubated with one of the following inhibitors: glibenclamide $(10 \mu \mathrm{M})$, selective blocker of $\mathrm{K}_{\mathrm{ATP}}$ channels; $\mathrm{BaCl}_{2}(1 \mathrm{mM})$, selective blocker of $\mathrm{K}_{\mathrm{IR}}$ channels; tetraethylammonium (TEA) $(1 \mathrm{mM}$ ) or charybdotoxin (ChTX) $0.1 \mu \mathrm{M}$, non-selective blockers of $\mathrm{BK}_{\mathrm{Ca}}$ channels, 4-aminopyridine (4-AP) $(1 \mathrm{mM})$, a selective blocker of $\mathrm{K}_{\mathrm{v}}$ channels, ouabain (100 $\mu \mathrm{M})$, a selective inhibitor of $\mathrm{Na}^{+}-\mathrm{K}^{+}$ATPase and apamin $(0.1 \mu \mathrm{M})$, a specific blocker of $\mathrm{SK}_{\mathrm{ca}}$ channels. The concentration used for each blocker/inhibitor of $\mathrm{K}^{+}$channels is sufficient to antagonize selectively those channels in arterial smooth muscle (Nelson and Quayle, 1995; Lagaud et al., 1999; Cortes et al., 2001; Oliveira et al., 2006). After stabilization of the tonic contraction induced by PHE, increasing cumulative concentrations of $\mathrm{KV}(1,10,30,100,300$, 500 and $1,000 \mu \mathrm{g} / \mathrm{ml}$ ) were added to the organ bath. The concentrations were chosen on the basis of previous studies in our laboratories (Santos et al., 2006; Santos et al., 2007).

Effect of $\mathrm{KV}$ on sustained contractions induced by $\mathrm{CaCl}_{2}$, and $\mathrm{Ca}^{2+}$ release from intracellular stores sensitive to phenylephrine and caffeine

To further investigate the mechanism of vasorelaxation induced by $\mathrm{KV}$, concentrationresponse curves to $\mathrm{CaCl}_{2}$ were constructed using endothelium-denuded rings (Lagaud et al., 1999). Briefly, the rings were pre-contracted with $60 \mathrm{mM} \mathrm{KCl}$ to confirm tissue viability. The Tyrode's solution was replaced with depolarizing Tyrode's solution $(\mathrm{KCl} 60 \mathrm{mM})$ nominally without $\mathrm{Ca}^{2+}$ (15 min). Thereafter, concentration-response curves to $\mathrm{CaCl}_{2}(1 \mu \mathrm{M}-10 \mathrm{mM})$ were constructed in the absence or presence of $\mathrm{KV}$. To determine whether $\mathrm{KV}$ could interfere with $\mathrm{Ca}^{2+}$ release from intracellular stores, the denuded rings were pre-contracted with $\mathrm{KCl}$, washed and exposed to $\mathrm{Ca}^{2+}$-free Tyrode's solution containing EGTA $(1 \mathrm{mM})$. The rings were then stimulated with phenylephrine $(10 \mu \mathrm{M})$ or caffeine $(20 \mathrm{mM})$ (Hugdins and Weiss, 1968). The contractions of both agonists were obtained in the absence (control) or after incubation with KV.

\section{Statistical analysis}

Two pharmacological parameters were analyzed in this study; $E_{\max }$ (Maximal effect generated by agonist) and $\mathrm{p} D_{2}\left(-\log \mathrm{EC}_{50}\right)$. Values are expressed as means \pm standard error of the mean (S.E.M.). Statistical analysis was performed using one-way analysis of variance (ANOVA) or Student's $t$-test using GraphPad Prism TM 4.0 version software, San Diego, CA, USA. Post hoc comparisons were performed after ANOVA using Dunnett's test as indicated in the text. The level of significance considered in all the tests was $0.05(P<0.05)$.

\section{Results}

Effect of $\mathrm{KV}$ on sustained contractions induced by phenylephrine or $\mathrm{KCl}$

$\mathrm{KV}$ inhibited the sustained contractions induced by phenylephrine (PHE, $10 \mu \mathrm{M})$ in isolated rat mesenteric arterial rings in a concentration dependent manner. The $\mathrm{p} D_{2}$ and $E_{\max }$ values of $\mathrm{KV}$ for contractions induced by PHE were $2.13 \pm 0.06$ and $58.3 \pm 1.7 \%$ for endothelium-intact and, 

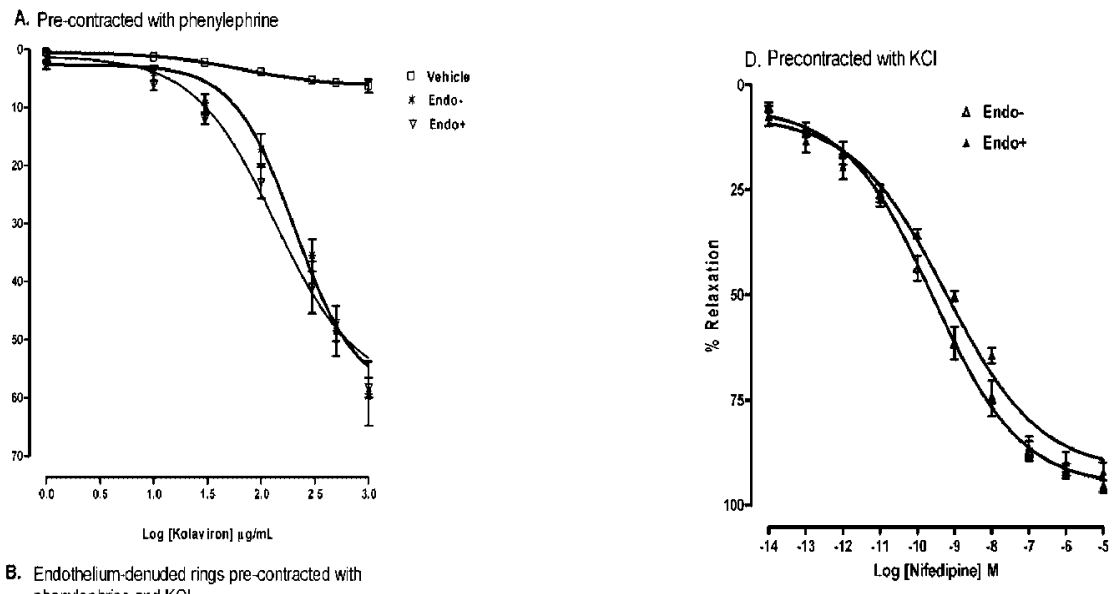

B. Endothelum-denuded rings pre-contracted with
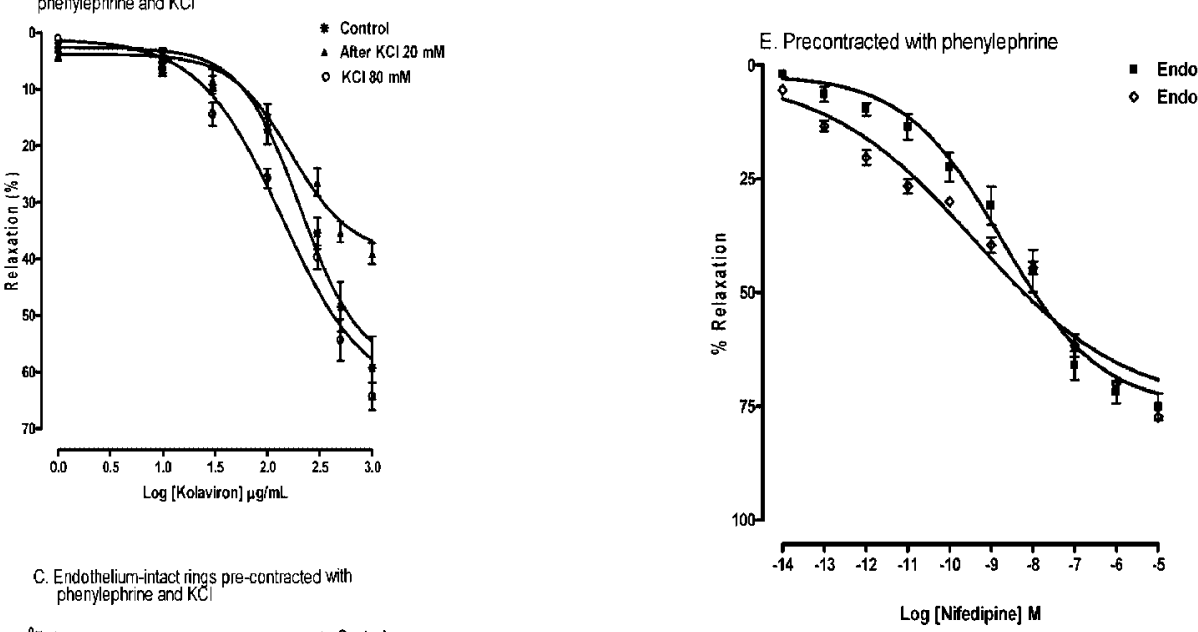

C. Endotheliurri-intact ings pre-contracted with

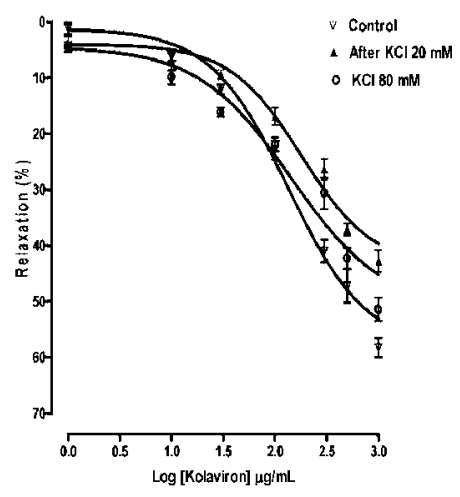

Log [Nifedipine] M

Fig. 2. Relaxation responses induced in isolated rat mesenteric arteries; (A) by kolaviron (KV) in endothelium-intact and -denuded rings pre-contracted with phenylephrine (PHE) (10 $\mu \mathrm{M})$, (B) denuded rings pre-constricted with either $\mathrm{KCl}(80 \mathrm{mM})$, or pre-incubated with $\mathrm{KCl}(20 \mathrm{mM})$ before constricted with $\mathrm{PHE},(\mathrm{C})$ intact rings pre-constricted with either $\mathrm{KCl}(80 \mathrm{mM})$, or pre-incubated with $\mathrm{KCl}(20 \mathrm{mM})$ before constricted with PHE, (D) by nifedipine in endothelium intact and denuded rings pre-contracted with $\mathrm{KCl}$ or PHE (E). 
Table 1. Effect of TEA (1 mM), glibenclamide (10 $\mu \mathrm{M}), \mathrm{BaCl}_{2}(1$ $\mathrm{mM})$, charybdotoxin $(0.1 \mu \mathrm{M}), \mathrm{KCl}(20 \mathrm{mM}), 4-\mathrm{AP}(1$ $\mathrm{mM})$, ouabain $(100 \mu \mathrm{M})$ and apamin $(0.1 \mu \mathrm{M})$ on $E_{\max }$ (\%) and $\mathrm{p} D_{2}$ values of kolaviron (KV)-induced relaxant responses in endothelium-denuded mesenteric rings pre-contracted with phenylephrine $(10 \mu \mathrm{M})$

\begin{tabular}{lcc}
\hline \multicolumn{1}{c}{ Groups } & $E_{\max }(\%)$ & $\mathrm{p} D_{2}$ \\
\hline Control & $59.3 \pm 5.5$ & $2.48 \pm 0.05$ \\
$\mathrm{KCl}(20 \mathrm{mM})$ & $39.0 \pm 1.9^{*}$ & $1.95 \pm 0.06^{*}$ \\
TEA $(1 \mathrm{mM})$ & $35.4 \pm 1.7^{*}$ & $1.84 \pm 0.02^{*}$ \\
Glibenclamide $(10 \mu \mathrm{M})$ & $53.8 \pm 9.2$ & $2.37 \pm 0.05$ \\
$\mathrm{BaCl}_{2}(1 \mathrm{mM})$ & $52.9 \pm 3.5$ & $2.26 \pm 0.06$ \\
Charybdotoxin $(0.1 \mu \mathrm{M})$ & $39.0 \pm 1.7^{*}$ & $2.01 \pm 0.05^{*}$ \\
4-AP $(1 \mathrm{mM})$ & $43.5 \pm 1.4^{*}$ & $2.29 \pm 0.03$ \\
Charybdotoxin $+4-\mathrm{AP}$ & $35.4 \pm 1.8^{*}$ & $1.86 \pm 0.04^{*}$ \\
Ouabain $(100 \mu \mathrm{M})$ & $56.1 \pm 1.4$ & $2.20 \pm 0.04$ \\
Apamin $(0.1 \mu \mathrm{M})$ & $55.7 \pm 1.7$ & $2.25 \pm 0.03$ \\
\hline
\end{tabular}

$\overline{\text { Values are the Mean } \pm \text { S.E.M., } \mathrm{n}=6-8 \text { experiments. }{ }^{\star} \text { Significantly }}$ different from control $(P<0.05)$. ANOVA followed by Dunnett's Multiple Comparison Test.

$2.48 \pm 0.05$ and $59.3 \pm 5.5 \%$, for denuded rings, respectively (Fig. $2 \mathrm{~A}$ ). The $\mathrm{p} D_{2}$ and $E_{\max }$ values of $\mathrm{KV}$ for PHE-induced contractions did not differ significantly in endothelium-intact from denuded rings. Similarly, no significant difference $(P>0.05)$ was found in the $\mathrm{p} D_{2}$ and $E_{\max }$ values of $\mathrm{KV}$ for $\mathrm{KCl}$-induced contractions in endothelium-intact $(2.09 \pm 0.04$ and $57.4 \pm 2.3 \%)$ when compared with denuded $(2.14 \pm 0.05$ and $64.3 \pm 2.4 \%)$ rings, respectively (Figs. $2 \mathrm{~B}$ and $2 \mathrm{C}$ ). The effect of the solvent (vehicle) used to prepare KV was insignificant with $E_{\max }$ value of $6.3 \pm 1.1 \%$ (Fig. 2A). Nifedipine significantly relaxed $\mathrm{KCl}$-induced tonic contraction in intact and denuded rings $\left(\mathrm{p} D_{2}\right.$ and $E_{\max }$ values $=9.23 \pm 0.08$ and $92.0 \pm 2.1 \%, 9.58 \pm 0.07$ and $95.6 \pm 1.5 \%$, respectively), but its relaxation of PHE-induced contraction was lesser ( $\mathrm{p} D_{2}$ and $E_{\max }$ values $=$ $8.89 \pm 0.10$ and $77.3 \pm 0.9 \%, 8.74 \pm 0.11$ and $75.1 \pm 3.0 \%$, for intact and denuded rings respectively) (Figs. 2D and $2 \mathrm{E}$ ).

Effect of $K V(10,30$ and $100 \mu \mathrm{g} / \mathrm{ml})$ on nifedipine-induced vasorelaxant response in denuded rings

As shown in Fig. 3A and Table 2, nifedipine $\left(10^{-14}-10^{-5} \mathrm{M}\right)$ concentration-dependently relaxed PHE-induced contraction of endothelium-denuded rings $\left(E_{\max }\right.$ and $\mathrm{p} D_{2}$ values $=75.1 \pm$ $3.0 \%$ and $8.74 \pm 0.11$, respectively). Furthermore, the relaxation induced by nifedipine remains unaltered when denuded rings where pre-incubated with $\mathrm{KV}$ at $10 \mu \mathrm{g} / \mathrm{ml}\left(E_{\max }\right.$ and $\mathrm{p} D_{2}$ values $=$ $79.3 \pm 1.0 \%$ and $8.51 \pm 0.04$, respectively $)$ and, $K V$ at $30 \mu \mathrm{g} / \mathrm{ml}\left(E_{\max }\right.$ and $\mathrm{p} D_{2}$ values $=80.2 \pm 2.0 \%$ and $8.54 \pm 0.09$, respectively). However, $\mathrm{KV}$ at $100 \mu \mathrm{g} / \mathrm{ml}$ shifted the concentration-response curve to nifedipine to the left with significant increases $(P<0.05)$ in $E_{\max }$ and $\mathrm{p} D_{2}$ values $(97.6 \pm$ $1.2 \%$ and $9.49 \pm 0.02$, respectively) (Fig. $3 \mathrm{~B}$ and Table 2 ).

\section{Effect of $K^{+}$channel blockers on the vasorelaxant response induced by $K V$}

In denuded rings pre-contracted with $\mathrm{PHE}$ in the presence of $\mathrm{KCl} 20 \mathrm{mM}$, the concentrationresponse curve for KV was significantly shifted to the right with decreased $E_{\max }$ and $\mathrm{p} D_{2}$ values 

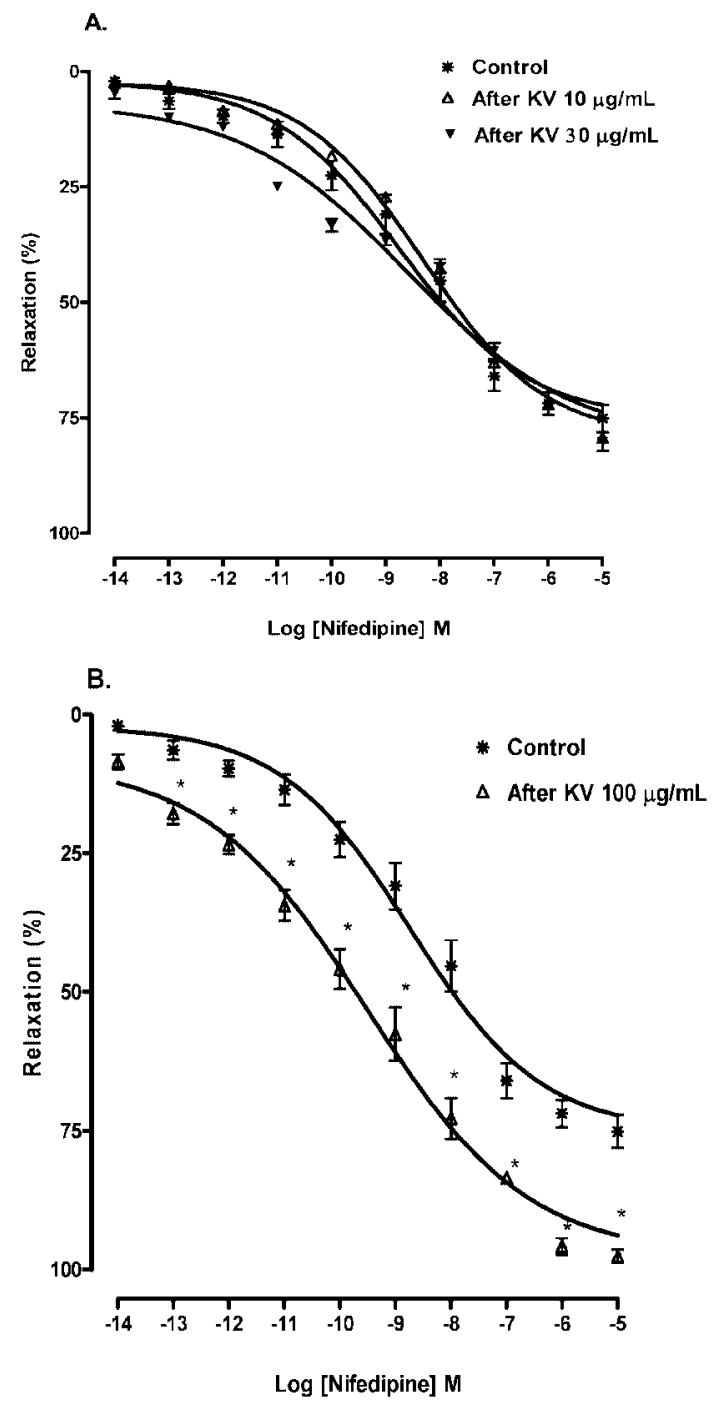

Fig. 3. Effects of kolaviron (KV) (10 and $30 \mu \mathrm{g} / \mathrm{ml})$ (A) and, $100 \mu \mathrm{g} / \mathrm{ml}$ (B) pre-incubated for $30 \mathrm{~min}$ on nifedipine-induced relaxant responses in denuded mesenteric rings. Steady tension was evoked by phenylephrine $(10 \mu \mathrm{M})$ and nifedipine $\left(10^{-14}-10^{-5} \mathrm{M}\right)$ was added cumulatively. Control, represents rings that were relaxed by nifedipine in the absence of KV. *, Significantly different from control $(P<0.05)$, ANOVA followed by Dunnett's multiple comparison test.

$=39.0 \pm 1.9 \%$ and $1.95 \pm 0.06$, respectively when compared to the control $(59.3 \pm 5.5 \%$ and $2.48 \pm$ 0.05 , respectively) (Fig. $2 \mathrm{~B}$ and Table 1 ), indicating the involvement of $\mathrm{K}^{+}$channels in the vasorelaxant effects of KV. Furthermore, in denuded rings pre-incubated with TEA (1 mM), ChTX $(0.1 \mu \mathrm{M}), 4$-AP $(1 \mathrm{mM})$ and ChTX + 4-AP before contracted with PHE, produced a rightward displacement of the concentration-response curves for KV with decreased $E_{\max }$ and $\mathrm{p} D_{2}$ values $=35.4 \pm 1.7 \%$ and $1.84 \pm 0.02,39.0 \pm 1.7 \%$ and $2.01 \pm 0.05,43.5 \pm 1.4 \%$ and $2.29 \pm 0.03$, $35.4 \pm 1.8 \%$ and $1.86 \pm 0.04$, respectively (Fig. 4 and Table 1 ). On the other hand, glibenclamide 
Table 2. Effect of pre-incubation of KV $(10,30$ and $100 \mu \mathrm{g} / \mathrm{ml})$ on the $E_{\max }$ and $\mathrm{p} D_{2}$ values of nifedipine-induced relaxant responses in denuded rat mesenteric rings pre-contracted with phenylephrine $(10 \mu \mathrm{M})$

\begin{tabular}{llc}
\hline \multicolumn{1}{c}{ Groups } & \multicolumn{1}{c}{$E_{\max }(\%)$} & $\mathrm{p} D_{2}$ \\
\hline Control & $75.1 \pm 3.0$ & $8.74 \pm 0.11$ \\
After KV $(10 \mu \mathrm{g} / \mathrm{ml})$ & $79.3 \pm 1.0$ & $8.51 \pm 0.04$ \\
After KV $(30 \mu \mathrm{g} / \mathrm{ml})$ & $80.2 \pm 2.0$ & $8.54 \pm 0.09$ \\
After KV $(100 \mu \mathrm{g} / \mathrm{ml})$ & $97.6 \pm 1.2^{\star}$ & $9.49 \pm 0.02^{*}$ \\
Values are the Mean \pm S.E.M., $\mathrm{n}=6$ experiments. * Significantly \\
different from control $(P<0.05)$. ANOVA followed by Dunnett's \\
Multiple Comparison Test.
\end{tabular}

$(10 \mu \mathrm{M}), \mathrm{BaCl}_{2}(1 \mathrm{mM})$, apamin $(0.1 \mu \mathrm{M})$ and ouabain $(100 \mu \mathrm{M})$ did not alter the vasorelaxant effects of $\mathrm{KV}$ in the denuded rings (Fig. 4).

Effect of $\mathrm{KV}$ on $\mathrm{CaCl}_{2}$-induced contractile response and $\mathrm{Ca}^{2+}$ release from intracellular stores in endothelium denuded rings

In Fig. 5, pre-incubation of endothelium denuded rings with $\mathrm{KV}$ attenuated $\mathrm{CaCl}_{2}$-induced contraction in $\mathrm{Ca}^{2+}$-free medium containing $\mathrm{KCl} 60 \mathrm{mM}$. $\mathrm{CaCl}_{2}$-induced a concentrationdependent contraction of mesenteric rings $\left(E_{\max }=100 \% ; \mathrm{p} D_{2}=3.45 \pm 0.05\right.$, control, Table 3$)$. Preincubation of the rings with $\mathrm{KV}$ at $1,10,30,100,300,500$ and $1,000 \mu \mathrm{g} / \mathrm{ml}$ altered the concentration-response curves of $\mathrm{CaCl}_{2}$, but with significant effects $(P<0.05)$ at any concentrations of $\mathrm{KV}$ (Fig. 5). The effects of $\mathrm{KV}$ on the $E_{\max }$ and $\mathrm{p} D_{2}$ values for $\mathrm{CaCl}_{2}$-induced contractions are given in Table 3 . Figure 6 shows that KV significantly $(P<0.05)$ antagonized the transient contractions induced by $\mathrm{PHE}$ in endothelium denuded rings in $\mathrm{Ca}^{2+}$-free media containing EGTA $(1 \mathrm{mM})$. In contrast, KV produced no significant effect $(P>0.05)$ on the transient contractions induced by caffeine $(20 \mathrm{mM})$ under similar conditions.

\section{Discussion}

The present study provides the first direct evidence that KV induces vasorelaxation in isolated rat blood vessels. Our findings indicate that $\mathrm{KV}$ elicits a concentration-dependent relaxation of rat superior mesenteric arteries that is mediated by the blockade of $\mathrm{Ca}^{2+}$ influx from extracellular medium as well as inhibition of $\mathrm{Ca}^{2+}$ release from intracellular stores sensitive to phenylephrine. In addition, the vasorelaxant effect of $\mathrm{KV}$ is linked to the opening of $\mathrm{K}^{+}$ channels sensitive to 4-aminopyridine and charybdotoxin.

The $\mathrm{p} D_{2}$ and $E_{\max }$ values of $\mathrm{KV}$ for inhibiting the $\mathrm{PHE}$ or $\mathrm{KCl}$ induced contractions of rat mesenteric arteries with or without functional endothelium are similar, which suggest that the vasorelaxant effects of $\mathrm{KV}$ are independent of endothelium. Furthermore, the $\mathrm{p} D_{2}$ and $E_{\max }$ values of nifedipine on intact or denuded rings pre-contracted with $\mathrm{PHE}$ or $\mathrm{KCl}$ were higher than with KV, indicating that nifedipine may be a better vasorelaxant agent. We investigated the possible link between $\mathrm{KV}$-induced vasorelaxation and the inhibition of $\mathrm{Ca}^{2+}$ influx from the extracellular medium. We observed that $\mathrm{CaCl}_{2}$-induced contractions in $\mathrm{Ca}^{2+}$-free media 

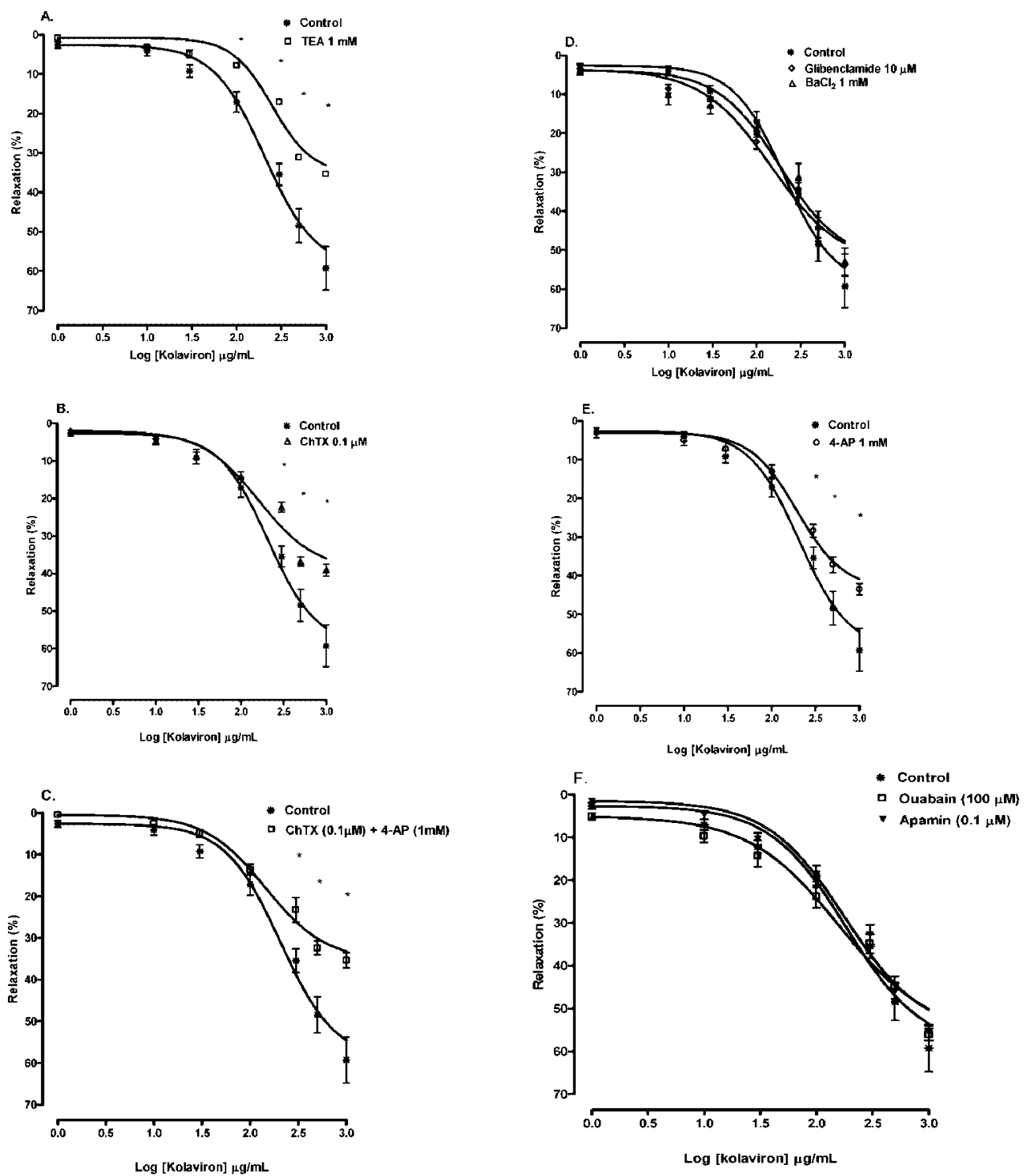

Fig. 4. Relaxation responses induced by kolaviron (KV) on denuded rat mesenteric arterial rings precontracted with phenylephrine in the presence of tetraethylammonium (TEA) (1 mM) (A), charybdotoxin (ChTX) $(0.1 \mu \mathrm{M})(\mathrm{B})$, ChTX + 4-aminopyridine (4-AP) (1 $\mathrm{mM})(\mathrm{C})$, glibenclamide $(10 \mu \mathrm{M})$ and $\mathrm{BaCl}_{2}(1 \mathrm{mM})(\mathrm{D})$, 4-AP $(1 \mathrm{mM})(\mathrm{E})$ and, ouabain $(100 \mu \mathrm{M})$ and apamin $(0.1 \mu \mathrm{M})(\mathrm{F})$. The rings were pre-incubated with the inhibitors for $30 \mathrm{~min}$. Steady tension was evoked by phenylephrine $(10 \mu \mathrm{M})$ and $\mathrm{KV}(1,10,30,100,300,500$ and 1,000 $\mu \mathrm{g} /$ $\mathrm{ml}$ ) was added cumulatively. *, Significantly different from control $(P<0.05)$, ANOVA followed by Dunnett's multiple comparison test.

containing $\mathrm{KCl} 60 \mathrm{mM}$ were significantly inhibited in a concentration-dependent manner by $\mathrm{KV}$. The rightward shift in the concentration-response curves for $\mathrm{CaCl}_{2}$ with a decrease in the $E_{\max }$ values, indicates that the biflavonoid behaves as a calcium antagonist. These results support the notion that $\mathrm{KV}$ can block $\mathrm{Ca}^{2+}$ influx through $\mathrm{Ca}^{2+}$ channels present in the vascular smooth 


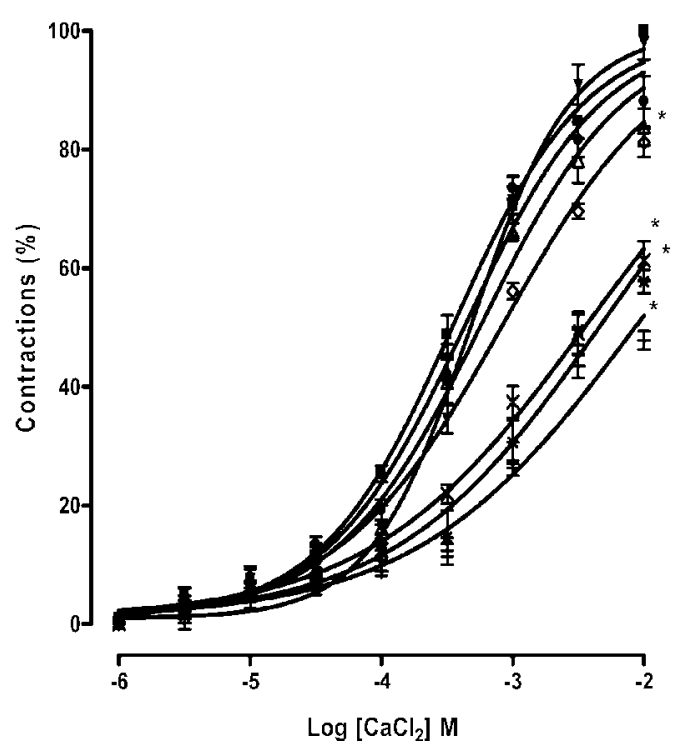

Fig. 5. Effect of kolaviron (KV) on $\mathrm{CaCl}_{2}$-induced contractile response in endotheliumdenuded mesenteric arterial rings. Concentration-response curves for $\mathrm{CaCl}_{2}$ were determined in $\mathrm{Ca}^{2+}$-free solution containing $\mathrm{KCl}(60 \mathrm{mM})$. The curves were determined in the absence (control) and after incubation with $\mathrm{KV}(1,10,30,100,300$, 500 and $1,000 \mu \mathrm{g} / \mathrm{ml})$. *, Significantly different from control $(P<0.05)$, ANOVA followed by Dunnett's multiple comparison test.

Table 3. Effect of $\mathrm{KV}$ on $E_{\max }$ and $\mathrm{p} D_{2}$ for $\mathrm{CaCl}_{2}$-induced contraction in endothelium denuded mesenteric rings in $\mathrm{Ca}^{2+}$-free medium

\begin{tabular}{ccl}
\hline $\mathrm{KV}(\mu \mathrm{g} / \mathrm{ml})$ & $\mathrm{p} D_{2}$ & $E_{\max }(\%)$ \\
\hline Control & $3.45 \pm 0.05$ & 100 \\
1 & $3.31 \pm 0.03$ & $98.1 \pm 2.9$ \\
10 & $3.56 \pm 0.04$ & $88.1 \pm 4.2$ \\
30 & $3.24 \pm 0.04$ & $83.8 \pm 3.2$ \\
100 & $2.80 \pm 0.06^{*}$ & $74.2 \pm 2.4^{*}$ \\
300 & $2.63 \pm 0.09^{*}$ & $61.3 \pm 3.2^{\star}$ \\
500 & $2.33 \pm 0.07^{*}$ & $57.7 \pm 1.9^{*}$ \\
1000 & $2.01 \pm 0.11^{*}$ & $47.8 \pm 1.6^{*}$
\end{tabular}

Values are the Mean \pm S.E.M., $n=42$ for control; $n=6$ for others. *Significantly different from control $(P<0.05)$. ANOVA followed by Dunnett's Multiple Comparison Test.

muscle cells (VSMCs). However, this behaviour does not rule out the possibility that KV may reduce the sensitivity of the contractile filaments to $\mathrm{Ca}^{2+}$. Contractions of VSMCs induced by $\mathrm{KCl}$ rely almost exclusively on $\mathrm{Ca}^{2+}$ influx through activation of voltage-sensitive channels 


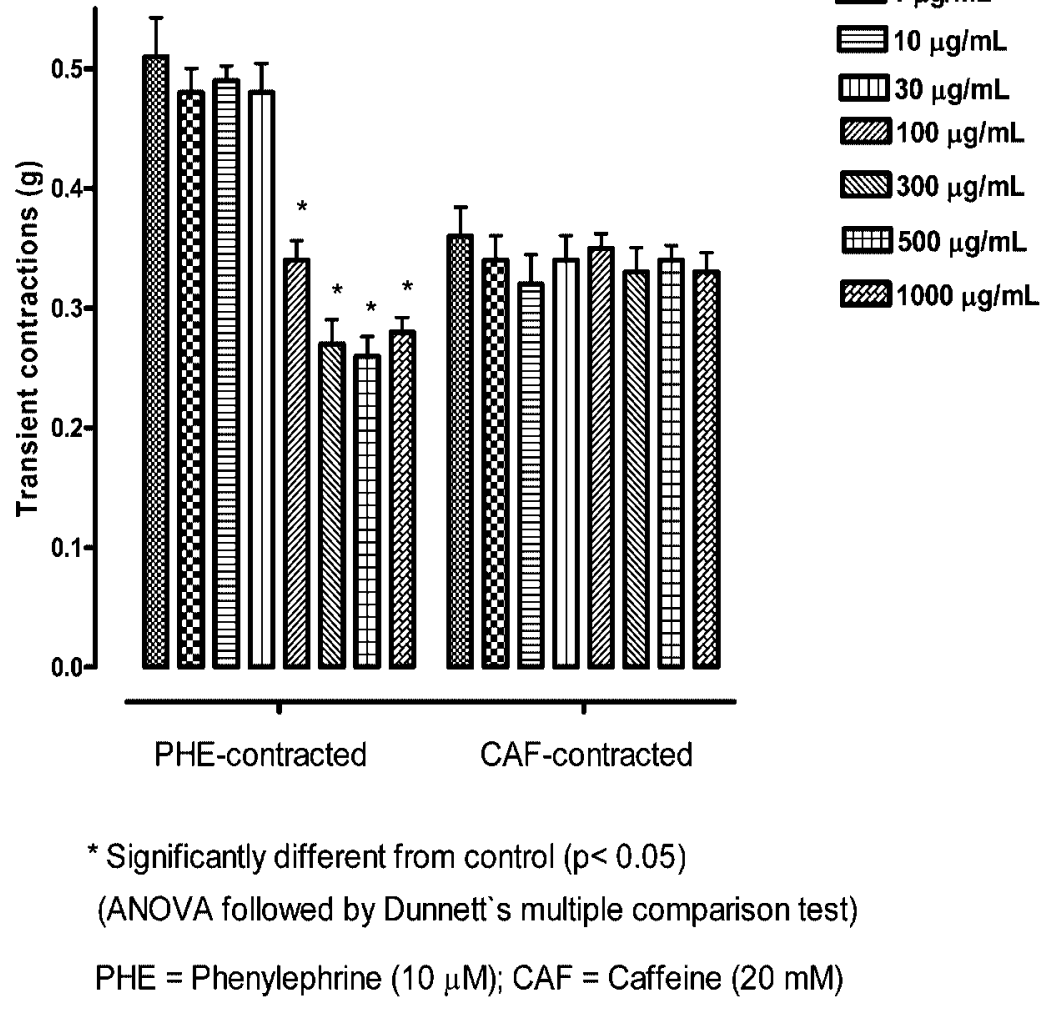

Fig. 6. Effect of $\mathrm{KV}(1,10,30,100,300,500$ and $1,000 \mu \mathrm{g} / \mathrm{ml})$ on phenylephrine $(10 \mu \mathrm{M})$ and caffeine $(20 \mathrm{mM})$ induced transient contractions in endothelium-denuded mesenteric arterial rings in $\mathrm{Ca}^{2+}$-free medium containing EGTA $(1 \mathrm{mM})$. *, Significantly different from control $(P<0.05)$, ANOVA followed by Dunnett's multiple comparison test.

(Hirata et al., 1998), whereas contractions induced by PHE are mediated by an increase in $\mathrm{Ca}^{2+}$ influx through both receptor-operated channels (Lee et al., 2001a) and voltage-sensitive channels (Eckert et al., 2000; Lee et al., 2001b). Since KV relaxed mesenteric rings precontracted with $\mathrm{PHE}$ and $\mathrm{KCl}(80 \mathrm{mM})$ with statistically similar $E_{\max }$ and $\mathrm{p} D_{2}$ values, it could be suggested that the biflavonoid blocks $\mathrm{Ca}^{2+}$ influx through interference with both voltage- and receptor-operated channels. This led us to investigate whether KV could exert its vasorelaxant effects by interfering with the release of intracellular calcium, $\left[\mathrm{Ca}^{2+}\right]_{\mathrm{i}}$ via the phosphoinositidedependent or -independent pathway following receptors activation. In $\mathrm{Ca}^{2+}$-free media containing EGTA, the biflavonoid significantly decreased the transient contractions induced by PHE, which stimulates inositol-1,4,5-triphosphate $\left(\mathrm{IP}_{3}\right)$-dependent $\mathrm{Ca}^{2+}$ release from intracellular stores (Leijten and van Breemen, 1984), whereas, the caffeine-induced contractions, which releases $\left[\mathrm{Ca}^{2+}\right]_{i}$ by an $\left(\mathrm{IP}_{3}\right)$-independent mechanism (Standen et al., 1989) were unaltered. Thus, it seems likely that the vascular effects of $\mathrm{KV}$ involve a reduction in $\mathrm{Ca}^{2+}$ release from 
intracellular stores sensitive to PHE. This result does not rule out the possibility that KV may interfere with other elements in the sarco-endoplasmic reticulum, especially the $\mathrm{Ca}^{2+}$-ATPases. This observation needs further evaluation.

In order to analyze the contribution of different types of $\mathrm{K}^{+}$channels to the $\mathrm{KV}$-induced endothelium-independent relaxation in the mesenteric rings, we used agents that are known to possess a $\mathrm{K}^{+}$channel-blocking activity. Glibenclamide is known to be one of the most selective blockers of $\mathrm{K}_{\mathrm{ATP}}$ channels, but it can also block voltage-dependent $\mathrm{K}^{+}\left(\mathrm{K}_{\mathrm{V}}\right)$ channels in concentrations higher than $10 \mu \mathrm{M}$ (Schaffer et al., 1999; Schuldt et al., 2005). In the present study, glibenclamide did not produce any significant effect on concentration-response curves of $\mathrm{KV}$, suggesting that $\mathrm{K}_{\mathrm{ATP}}$ channels are not involved in the vasorelaxation induced by the biflavonoid. Similarly, neither apamin, $\mathrm{BaCl}_{2}$ nor ouabain, blockers of $\mathrm{SK}_{\mathrm{ca}}, \mathrm{K}_{\mathrm{IR}}$ channels and $\mathrm{Na}^{+}-\mathrm{K}^{+}$ATPase, respectively (Cortes et al., 2001; Tirapelli et al., 2004; Oliveira et al., 2006) affected the concentration-response curves of KV, hence these channels and the ATPase are not involved in the vasorelaxant effects of KV. TEA and ChTX, at these concentrations are nonselective blockers of large and intermediate conductance $\mathrm{Ca}^{2+}$-activated $\mathrm{K}^{+}$channels $\left(\mathrm{BK}_{\mathrm{Ca}}\right)$. Both TEA and ChTX significantly inhibited the concentration-response curves of KV, indicating that the opening of these channels is required for the vasorelaxation induced by the biflavonoid. Similarly, 4-AP, a selective blocker of voltage-dependent $\mathrm{K}^{+}$-channels significantly affected KVinduced relaxation, thus the activation of $\mathrm{K}_{\mathrm{v}}$ channels also plays a role in $\mathrm{KV}$-induced relaxation.

Clinically, $\mathrm{Ca}^{2+}$ antagonists and $\mathrm{K}^{+}$channels openers are used for the treatment of hypertension due to their ability to induce vascular smooth muscle relaxation. It is therefore possible to suggest, considering its vascular effects, that KV is a potential agent that could exert antihypertensive action in vivo. It should be noted that $\mathrm{KV}(100 \mu \mathrm{g} / \mathrm{ml})$ potentiates the relaxant effect of nifedipine in denuded rings pre-contracted with PHE. This observation calls for a caution in the intake of Garcinia kola seeds, which contain $\mathrm{KV}$, by hypertensive patients on $\mathrm{Ca}^{2+}$ channel blockers in order to avoid hypotension.

In summary, the vasorelaxation-induced by KV occurs through an endothelium-independent mechanism that involves the blockade of extracellular $\mathrm{Ca}^{2+}$ influx by interfering with both voltage- and receptor-operated channels. In addition, it inhibited $\mathrm{Ca}^{2+}$ release from intracellular stores via the $\mathrm{IP}_{3}$ pathway and, opened $\mathrm{BK}_{\mathrm{Ca}}$ and $\mathrm{K}_{\mathrm{v}}$ channels with a resultant membrane hyperpolarization/ repolarization. However, further studies are needed to evaluate the involvement of other $\mathrm{K}^{+}$channel-independent pathways in the vasorelaxation induced by $\mathrm{KV}$.

\section{Acknowledgements}

This work was supported by one-year postdoctoral fellowship from the Brazilian National Council for Scientific and Technological Development (CNPq) and The Academy of Sciences for the Developing World (TWAS). Authors are CNPq Fellows.

\section{References}

Adaramoye, O.A., Farombi, E.O., Adeyemi, E.O. and Emerole, G.O. (2005a). Inhibition of human low- 
density lipoprotein oxidation by flavonoids of Garcinia kola seeds. Pak. J. Med. Sci. 21: 331-339. Adaramoye, O.A., Nwaneri, V.O., Anyanwu, K.C., Farombi, E.O. and Emerole, G.O. (2005b). Possible anti- atherogenic effect of kolaviron (A Garcinia kola seed extract) in hypercholesterolemic rats. Clin. Exp. Pharmacol. Physiol. 32: 40-46.

Adaramoye, O.A. and Adeyemi, E.O. (2006a). Hepatoprotection of D-galactosamine-induced toxicity in mice by purified fractions from Garcinia kola seed. Basic Clin. Pharmacol. Toxicol. 98: 135-141.

Adaramoye, O.A. and Adeyemi, E.O. (2006b). Hypoglycaemic and hypolipidaemic effects of fractions from kolaviron, a biflavonoid complex from Garcinia Kola in streptozotocin-induced diabetes mellitus rats. J. Pharm. Pharmacol. 18: 121-128.

Altura, B.M. and Altura, B.T. (1970). Calcium content and force of drug-induced contractions of arterial muscle during recovery in vitro. Proc. Soc. Exp. Biol. Med. 135: 739-744.

Côrtes, S.F., Rezende, B.A., Corriu, C., Medeiros, I.A., Teixeira, M.M., Lopes, M.J. and Lemos, V.S. (2001). Pharmacological evidence for the activation of potassium channels as the mechanism involved in the hypotensive and vasorelaxant effect of dioclein in rat small resistance arteries. Br. J. Pharmacol. 133: 849-858.

Cotterhill, P.J., Scheinmann, F. and Stenhouse, T.A. (1978). Extractives from Guttiferae: kolaflavanone, a new biflavanone from the nuts of Garcinia kola Heckel. J. Chem. Soc. Perkin Trans. 1: 246.

Eckert, R.E., Karsten, A.J., Utz, J. and Ziegler, M. (2000). Regulation of renal artery smooth muscle tone by alpha1-adrenoceptors: role of voltage-gated calcium channels and intracellular calcium stores. Urol. Res. 28: 122-127.

Gordana, S.C., Sonja, M.D., Jasna, M.C. and Vesna, T.T. (2004). Antioxidant properties of marigold extracts. Food Res. Int. 37: 643-650.

Hudgins, A. and Weiss, G. (1968). Different effects of $\mathrm{Ca}^{2+}$ removal upon vascular smooth muscle contraction induced by norepinephrine, histamine and potassium. J. Pharmacol. Exp. Ther. 159: 91-97.

Hirata, S., Enoki, T., Kitamura, R., Vinh, V.H., Nakamura, K. and Mori, K. (1998). Effects of isoflurane on receptor-operated $\mathrm{Ca}^{2+}$ channels in rat aortic smooth muscle. Br. J. Anaesth. 81: 578-583.

Iwu, M.M. and Igboko, O.A. (1982). Flavonoids of Garcinia kola seeds. J. Nat. Prod. 45: 650-651.

Iwu, M.M., Igboko, O.A., Okunji, C.O. and Tempesta, M.S. (1990). Anti-diabetic and aldose reductase activities of biflavanones of Garcinia kola. J. Pharm. Pharmacol. 42: 290-292.

Iwu, M.M., Igboko, O.A., Onwuchekwa, U. and Okunji, C.O. (1987). Evaluation of the anti-hepatotoxicity of the biflavonoids of Garcinia kola seeds. J. Ethnopharmacol. 21: 127-138.

Lagaud, G.J., Randriamboavonjy, V., Roul, G., Stoclet, J.C. and Andriantsitohaina, R. (1999). Mechanism of $\mathrm{Ca}^{2+}$ release and entry during contraction elicited by norepinephrine in rat resistance arteries. Am. J. Physiol. 276: H300-H308.

Lans, C., Georges, K. and Brown, G. (2007). Non-experimental validation of ethno-veterinary plants and indigenous knowledge used for backyard pigs and chickens in Trinidad and Tobago. Trop. Anim. Health Prod. 39:375-385.

Lee, C.K., Park, K.K., Lim, S.S., Park, J.H. and Chung, W.Y. (2007). Effects of the licorice extract against tumor growth and cisplatin-induced toxicity in a mouse xenograft model of colon cancer. Biol. Pharm. Bull. 30:2191-2195.

Lee, C.H., Poburko, D., Sahota, P., Sandhu, J., Ruehlmann, D.O. and van Breemen, C. (2001a). The mechanism of phenylephrine-mediated $\left[\mathrm{Ca}^{2+}\right]_{i}$ oscillations underlying tonic contraction in the rabbit inferior vena cava. J. Physiol. 534: 641-650.

Lee, C.N., Wong, K.L., Liu, J.C., Chen, Y.J., Cheng, J.T. and Chan, P. (2001b). Inhibitory effect of stevioside on calcium influx to produce antihypertension. Planta Med. 67: 796-799.

Leijten, P.A. and van Breemen, C. (1984). The effects of caffeine on the noradrenaline-sensitive calcium store in rabbit aorta. J. Physiol. (Lond.) 357: 327-339.

Li-chem, W., Hsiu-Wen, H., Yun-Chen, C., Chih-Chung, C., Yu-In, L. and Ja-an, A.H. (2006). Antioxidant 
and antiproliferative activities of red pitaya. Food Chem. 95: 319-327.

Nelson, M.T. and Quayle, J.M. (1995). Physiological roles and properties of potassium channels in arterial smooth muscle. Am. J. Physiol. 268: C799-C822.

Oliveira, A.P., Furtado, F.F., da Silva, M.S., Tavares, J.F., Mafra, R.A., Araújo, D.A., Cruz, J.S. and Medeiros, I.A. (2006). Calcium channel blockade as a target for the cardiovascular effects induced by the 8 (17), 12E, 14-labdatrien-18-oic acid (labdane-302). Vascul. Pharmacol. 44: 338344.

Priviero, F.B., Teixeira, C.E., Toque, H.A., Claudino, M.A., Webb, R.C., De Nucci, G., Zanesco, A. and Antunes, E. (2006). Vasorelaxing effects of propranolol in rat aorta and mesenteric artery: a role for nitric oxide and calcium entry blockade. Clin. Exp. Pharmacol. Physiol. 33: 448-455.

Santos, M.R., Nascimento, N.M., Antoniolli, A.R. and Medeiros, I.A. (2006). Endothelium-derived factors and $\mathrm{K}^{+}$channels are involved in the vasorelaxation induced by Sida cordifolia $\mathrm{L}$. in the rat superior mesenteric artery. Pharmazie 61: 466-469.

Santos, M.R., Carvalho, A.A., Medeiros, I.A., Alves, P.B., Marchioro, M. and Antoniolli, A.R. (2007). Cardiovascular effects of Hyptis fruticosa essential oil in rats. Fitoterapia 78: 186-191.

Schaffer, P., Pelzmann, B., Bernhart, E., Lang, P., Mächler, H., Rigler, B. and Koidl, B. (1999). The sulphonylurea glibenclamide inhibits voltage dependent potassium currents in human atrial and ventricular myocytes. Br. J. Pharmacol. 128: 1175-1180.

Schuldt, E.Z., Bet, A.C., Hort, M.A., Ianssen, C., Maraschin, M., Ckless, K. and Ribeiro-do-Valle, R.M. (2005). An ethyl acetate fraction obtained from a Southern Brazilian red wine relaxes rat mesenteric arterial bed through hyperpolarization and NO-cGMP pathway. Vascul. Pharmacol. 43: $62-68$.

Standen, N.B., Quayle, J.M., Davies, N.W., Brayden, J.E., Huang, Y. and Nelson, M.T. (1989). Hyperpolarizing vasodilators activate ATP-sensitive $\mathrm{K}^{+}$channels in arterial smooth muscle. Sci. 14: $177-180$.

Tanaka, Y., Mochizuki, Y., Tanaka, H. and Shigenobu, K. (1999). Significant role of neuronal non-N-type calcium channels in the sympathetic neurogenic contraction of rat mesenteric artery. $\mathrm{Br}$. $J$. Pharmacol. 128: 1602-1608.

Tirapelli, C.R., Ambrosio, S.R., da Costa, F.B., Coutinho, S.T., de Oliveira. D.C. and de Oliveira. A.M. (2004). Analysis of the mechanisms underlying the vasorelaxant action of kaurenoic acid in the isolated rat aorta. Eur. J. Pharmacol. 492: 233-241.

Waterman, P.G. and Hussain, R.A. (1983). Systematic significance of xanthones, benzophenones and biflavonoids in Garcinia. Biochem. Sys. Ecol. 11: 21-30. 